\title{
Medical device-related pressure injury prevention in critically ill patients: nursing care
}

\author{
Prevenção de lesões por pressão relacionadas a dispositivos médicos em pacientes críticos: cuidados de enfermagem
}

Prevención de lesiones por presión relacionadas con dispositivos médicos en pacientes críticos: cuidados de enfermería

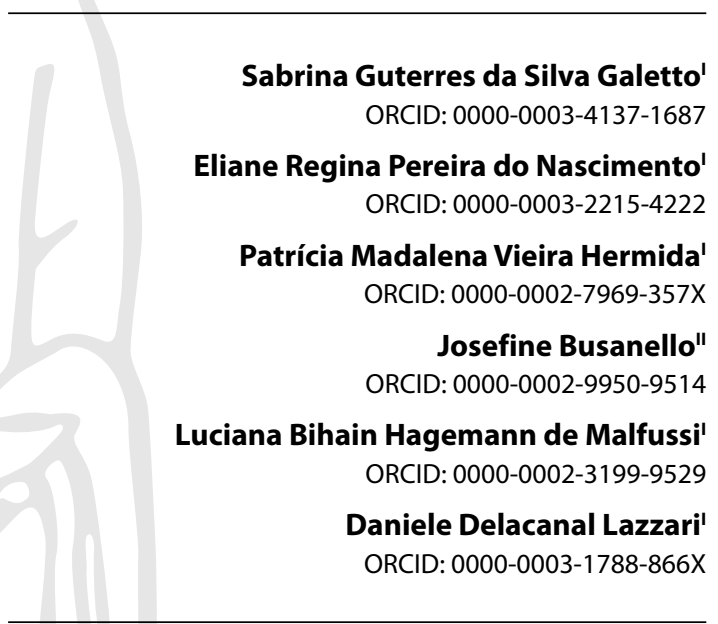

'Universidade Federal de Santa Catarina. Florianópolis, Santa Catarina, Brazil. "Universidade Federal do Pampa. Uruguaiana, Rio Grande do Sul, Brazil.

How to cite this article: Galetto SGS, Nascimento ERP, Hermida PMV, Busanello J, Malfussi LBH, Lazzari DD. Medical device-related pressure injury prevention in critically ill patients: nursing care.

Rev Bras Enferm. 2021;74(2):e20200062. http://doi.org/10.1590/0034-7167-2020-0062

Corresponding author:

Sabrina Guterres da Silva Galetto E-mail: sabrinaguterres@gmail.com

EDITOR IN CHIEF: Antonio José de Almeida Filho ASSOCIATE EDITOR: Hugo Fernandes

Submission: $06-13-2020$

Approval: $10-03-2020$

\section{ABSTRACT}

Objectives: to know the care implemented by the nursing team to prevent medical devicerelated pressure injuries in critically ill patients. Methods: this is a qualitative research conducted with 15 nursing professionals from Intensive Care Unit. Sampling was carried out by theoretical saturation. For data analysis, the Discourse of the Collective Subject technique was used. Results: six speeches emerged, whose central ideas were interventions for medical device-related pressure injury prevention: care in fixation; frequent repositioning; protection and padding of body areas in contact; preferences for flexible materials, when available; attention of professionals so that they do not comer under patients; early assessment and removal, when clinically possible. Final Considerations: nursing care was directed mainly to respiratory devices, catheters in general and monitoring equipment, indicating that professionals have the knowledge to provide safe assistance consistent with the literature. Descriptors: Nursing; Pressure Ulcer; Equipment and Supplies; Critical Care; Nursing Care.

\section{RESUMO}

Objetivos: conhecer os cuidados implementados pela equipe de enfermagem para prevenção de lesões por pressão relacionadas a dispositivos médicos em pacientes críticos. Métodos: pesquisa qualitativa, com 15 profissionais de enfermagem da Unidade de Terapia Intensiva. A amostragem foi por saturação teórica. Para análise dos dados, utilizou-se a técnica do Discurso do Sujeito Coletivo. Resultados: emergiram seis discursos, que tiveram como ideias centrais intervenções para prevenção das lesões por pressão relacionadas a dispositivos médicos: cuidados na fixação; reposicionamento frequente; proteção e acolchoamento das áreas corpóreas em contato; preferências por materiais flexíveis, quando disponíveis; atenção dos profissionais para que não fiquem sob o paciente; avaliação e remoção precoce, quando clinicamente possível. Considerações Finais: os cuidados de enfermagem foram direcionados principalmente a dispositivos respiratórios, cateteres em geral e equipamentos de monitorização, indicando que os profissionais possuem conhecimento para prestar uma assistência segura coerente com a literatura.

Descritores: Enfermagem; Lesão por Pressão; Equipamentos e Provisões; Cuidados Críticos; Cuidados de Enfermagem.

\section{RESUMEN}

Objetivos: conocer los cuidados implementados por el equipo de enfermería para prevenir lesiones por presión relacionadas con dispositivos médicos en pacientes críticos. Métodos: investigación cualitativa, con 15 profesionales de enfermería de la Unidad de Cuidados Intensivos. El muestreo fue por saturación teórica. Para el análisis de los datos se utilizó la técnica del Discurso Colectivo del Sujeto. Resultados: surgieron seis discursos, cuyas ideas centrales fueron intervenciones para la prevención de lesiones por presión relacionadas con dispositivos médicos: cuidado en la fijación; reposicionamiento frecuente; protección y acolchado de las zonas corporales en contacto; preferencias por materiales flexibles, cuando estén disponibles; atención de los profesionales para que no estén debajo del paciente; evaluación y remoción temprana, cuando sea clínicamente posible. Consideraciones Finales: la atención de enfermería se dirigió principalmente a dispositivos respiratorios, catéteres en general y equipos de monitoreo, lo que indica que los profesionales tienen el conocimiento para brindar una asistencia segura acorde con la literatura.

Descriptores: Enfermería; Úlcera por Presión; Equipos y Suministros; Cuidados Críticos; Atención de Enfermería. 


\section{INTRODUCTION}

Pressure injuries (PI), formerly known as bedsores, decubitus ulcers or pressure ulcers, are defined as changes in skin integrity that affect regions with bony prominences, especially caused by skin pressure, shear, and microclimate. Injuries resulting from device use, applied for diagnostic and therapeutic purposes, receive the nomenclature of medical device-related pressure injuries (MDR PI). Generally, they present the pattern or shape of the device, and should be categorized based on the PI classification criteria(1).

Although all individuals using medical devices are susceptible to these injuries, critical patients admitted to Intensive Care Units (ICU) typify those at high risk, as they are exposed to a range of devices for treatment and monitoring ${ }^{(2)}$. Moreover, they may present impaired sensory perception through sedative use, as well as edema, immobility, capillary fragility and longer hospital stay, which can potentially culminate the development of injuries ${ }^{(3-5)}$. A study conducted by Australian nurses revealed a hospital incidence of MDR PI of $27.9 \%, 68 \%$ of which in ICU patients ${ }^{(6)}$.

MDR PIs have received worldwide notoriety recently from the Coronavirus Disease pandemic (COVID-19). The emphasis on these injuries is associated with the considerable increase in intensive care patients, who depend on advanced ventilatory support and the uninterrupted use of personal protective equipment by health professionals, culminating in a higher incidence of these injuries ${ }^{(7)}$.

The publication of an international consensus on MDR PI, by health professionals and bioengineering experts, clarifies its etiology and encourages the development of technologies and clinical protocols that can be used to mitigate them. An important and innovative element of this work was strategy adoption to change health professionals' and managers' thinking about the need to prevent MDR PI, including global awareness about its causes, the scale of the problem and its financial implications ${ }^{(8)}$.

In this perspective, the advances in the practice of care in MDR PI prevention rescue the importance of nursing performance ${ }^{(3)}$. Especially in the context of intensive care, the nursing team provides uninterrupted assistance to critically ill patients, and is therefore able to identify their development early, adopt measures to prevent these adverse events and improve patient safety ${ }^{(9)}$.

A study carried out in Turkey analyzed the perceptions and interventions carried out by nurses for identifying patients at risk for MDR PI and preventing their occurrence. Most nurses $(80.1 \%)$ related device use to the development of these injuries; however, only $59.2 \%$ reported experience with interventions for their prevention ${ }^{(9)}$. The findings suggest that nurses may not be aware of the risk of MDR PI, indicating the need for permanent education and training programs for these professionals.

Although scientific production on the subject is growing, new studies should be developed in South America and, especially, in Brazil, given the scarcity of publications ${ }^{(10)}$. Therefore, this research can expand the knowledge on the subject in national and international literature, subsidizing nursing care.

\section{OBJECTIVES}

To know the care implemented by the nursing team to prevent medical device-related pressure injuries in critically ill patients.

\section{METHODS}

\section{Ethical aspects}

This study was approved by the Human Research Ethics Committee of Universidade Federal de Santa Catarina, and the ethical principles and postulates were observed according to the Resolution of the Brazilian National Health Council (CNS - Conselho Nacional de Saúde) 466/2012. All participants signed an Informed Consent Form. In order to preserve participant anonymity, the initials " $\mathrm{N}$ " (nurse) and "NT" (nursing technician) were adopted for their identification in DCS, plus the number corresponding to the interview sequence.

\section{Type of study}

This a descriptive and qualitative research, carried out with nursing professionals in an ICU and reported according to the consolidated criteria for reporting qualitative research (COREQ) recommendations.

\section{Methodological procedures}

Nursing professional working in the unit for at least half a year and in full exercise of their work practice were included. There was the exclusion of professionals who were on leave of any nature during the study period.

The nursing staff was composed of: 15 nurses, of whom 1 was in charge and 14 were in direct patient care, in addition to 38 mid-level professionals (nursing technicians). Thus, 15 professionals participated in the study, of which five nurses and 10 nursing technicians.

\section{Study setting}

This study took place in an ICU of a public teaching hospital in Santa Catarina, which had 10 beds for clinical and surgical admission of adults during the study.

\section{Data collection and organization}

Data collection took place between February and April 2018 through semi-structured interviews, conducted individually and recorded in MP3 format, based on the guiding question: what precautions do you take to prevent medical device-related PI?

Transcription was carried out immediately after each interview. The sampling was intentional, established by theoretical saturation ${ }^{(11)}$, based on seven steps: 1) making the "raw" data records available; 2) "immersing" in each record; 3) compile individual analyzes; 4) gathering themes and/or statements; 5) coding or naming the data;6) allocating themes and/or statements; 7) verifying theoretical saturation.

Following these assumptions, data saturation was reached in the sixth interview. However, data collection was extended until the fifteenth interview in order to strengthen saturation.

\section{Data analysis}

In data analysis, the Discourse of the Collective Subject (DCS) technique was used ${ }^{(12)}$, comprising four methodological figures: key expressions (KE), central ideas $(\mathrm{Cl})$, anchoring $(\mathrm{AC})$ and DCS itself. 
First, each statement was analyzed individually to identify the most significant passages, called KE. Afterwards, Cls were defined, which consist of a synthetic formulation of the researcher, a "semantic tag" that allows identifying the meanings attributed in each homogeneous set of KE.

There is a type of $\mathrm{Cl}$ called Anchoring, which presents itself when subjects rely on pre-existing knowledge to make sense of the unknown, usually an ideology or belief ${ }^{(12)}$. This methodological figure was not identified in the statements. Finally, DCS were built, written in the first person singular and elaborated from the meeting in a single speech/synthesis of KE with the same $\mathrm{Cl}$.

The qualitative and quantitative dimension of DCS was considered. In the first, DCS or collective testimony conveys a certain opinion, while in the second, the individual testimonies that contributed to its construction, based on $\mathrm{KE}$, are represented by the number or percentage, allowing to know the degree of sharing of opinions between the researched population ${ }^{(12)}$. Data organization and processing was carried out with the aid of QualiQuantiSoft software', version 1.3c.

\section{RESULTS}

Fifteen nursing professionals participated in the study, 10 nursing technicians and five nurses. Most participants were female $(n=11)$, and the mean age was 40 years. Training time for the position varied from 4 to 25 years (mean 16 years). The mean time working in intensive care was 9.6 years.

Training in the area and length of experience in the ICU had an average of 16 and 9.6 years, respectively. As for level of training, eight nursing technicians had completed higher education, six in nursing. In addition, three specialized in intensive care. All participating nurses had a master's degree, one was a doctor of nursing and another was pursuing a doctorate in nursing.

From individual testimonies about nursing care for medical device-related PI prevention, six Cls (Table 1) and their respective DCS emerged, originated from KE of the same sense.

Table 1- Central ideas about medical device-related pressure injury prevention, extracted from individual statements $(\mathrm{N}=15)$, Florianópolis, Santa Catarina, Brazil, 2018

\begin{tabular}{lc}
\hline Central ideas (CI) & $\mathbf{n}(\%)$ \\
\hline Nursing care when fixing devices & $12(80.0)$ \\
$\begin{array}{l}\text { Frequent device repositioning } \\
\begin{array}{l}\text { Protection and padding of body areas in contact with } \\
\text { medical devices }\end{array}\end{array}$ & $9(60.0)$ \\
$\begin{array}{l}\text { Replacement of rigid devices with flexible devices, when } \\
\text { available }\end{array}$ & $3(20.0)$ \\
$\begin{array}{l}\text { Professionals' attention so that devices do not come under } \\
\text { patients }\end{array}$ & $3(20.0)$ \\
$\begin{array}{l}\text { Early assessment and removal of devices, when clinically possible } \\
\text { P. }\end{array}$ & $1(6.6)$ \\
\hline
\end{tabular}

Greater representativeness was evidenced in DCS1, built from KE extracted from the testimony of $80 \%$ of professionals. The speech with the least representation was DCS 6, with 6.6\%, which does not exempt the importance of the care recommended in this speech. Regarding the qualitative dimension, a series of nursing care was identified in the six DCS for MDR PI prevention, commonly applicable in critically ill patients. Also, it is highlighted that in the presentation of the speeches, the term probe, commonly used by the professionals participating in the study, was used to name the bladder, enteric and gastric catheters.

\section{$\mathrm{CI} 1$ : Nursing care when fixing devices}

DCS1: here, in intensive care, care has been taken to secure devices more securely. For example, for nasoenteral and nasogastric tube there is a specific adhesive and a specific technique in which the finger is placed on the central part of the fixator to prevent it from being too close to the nasal columella. Then place it over the wing of the nose and the fixation is at an appropriate distance preventing you from pulling the probe upwards. You can also do the support fixation, on the shoulder, to decrease the weight and the traction force. The orotracheal tube can give two or three turns in the lace, so that it is at the height of the nose, at the same angle as the cartilage at the top of the ear, and does not pull. There is another way that fixes behind the head, and it stays the same way. Or you can use a "helmet", in which one more lacing is placed and a fixation is made on the top of the head, deflecting the lacing from the auricular region. There are other types of devices for fixing the tube, but it has never been used here. With regard to the bladder tube, the fixation is ideal to reduce the risk of injury by decreasing the weight and traction of the tube. Years ago, there was even a device to fix it, but people didn't like it because it came off the skin, so it turned out that a device was never standardized. (N1, N2, N3, N4, N5, NT1, NT2, NT3, NT4, NT6, NT7, NT9)

\section{CI2: Frequent device repositioning}

DCS2: I am careful to change the finger oximeter every time I go to check vital signs. He doesn't have a routine, but he could change his finger every two hours and every 24 hours change his hand. When you change the position, you notice that it has already been well marked there. In some patients it presses so hard that that end becomes cyanotic. When patients are awake, I always say "the oximeter, you can change with your fingers", because otherwise they won't move anymore. Regarding the electrodes, always in the bath I take it out and put it in another place to let that skin rest. The orotracheal tube in oral hygiene and shoelace change, you can move a little, with care, of course, but you can change places, leave more in the middle of the mouth or rotate between the labial commissures to avoid injury. Catheters, probes, we can certainly change their positions. The nasoenteral probe, for example, has to observe its fixation, if that area is too pressed it has to change, rotate, if it is closer to the left wing it moves a little to the right. This will prevent you from hurting by spending so much time pressing the same spot. (N2, N4, N5, NT2, NT3, NT5, NT6, NT7, NT8, NT9, NT10)

\section{Cl3: Protection and padding of body areas in contact with medical devices}

DCS3: the orotracheal tube, when I change the laces, I always put a gauze on my ear and when I have an injury, I put an EFC and a gauze. In the area of the lips, when I see that it is hurt or with edema, I place a gauze underneath. We have to improvise, put gauze or something to pad. But it is not even known whether it is 
helping or harming, because the gauze is not soft, it has its own issue that also ends up marking patients. Another thing is the hydrocolloid plate that can be used in many ways. The other day I cut out two strips and put them on patients' ears. When you are going to apply condom catheter before applying adhesive tape, this plate can also be used. When we used NIV oronasal masks, I would often put a small plaque at the base of the nose to protect that area, because necrosis was very frequent. Sometimes, even with a thinner plaque, which saves the region, favors recovery and does not leave a chronic trauma. That plate helps a lot to avoid injuries, even nasal damage to the enteral tube. For the lesion by the venous catheter, I have already used gauze film, which diverts the catheter and the region is somewhat protected. $(\mathrm{N} 2, \mathrm{~N} 3, \mathrm{~N} 4$, N5, NT2, NT3, NT4, NT9, NT10)

\section{Cl4: Replacement of rigid devices with flexible devices when available}

DCS4: I think that sometimes a poor-quality product comes to the hospital, material that you feel is a little more rigid, which is not so comfortable. In the case of NIV, perhaps if it were a slightly more malleable, more comfortable halter, perhaps it would not cause so much injury. Or the manufacturer should give options to offer less risk to patients. There are other materials that we could use. Perhaps it is not our reality because it is a public hospital, but it exists. So, I think if we had alternative materials to prevent injury to patients, it would be a good idea. (N4, NT4, NT7)

\section{CI5: Professionals' attention so that devices do not come under patients}

DCS5: sometimes a patient is on top of something loose in the bed and we don't notice it. We take care a lot, but it happens. Last week a patient had an injury to the electrode cable, it was very visible that it was the cable, in the breast region. That was certainly an oversight. If a patient is going to make the decubitus change, take care not to get the probes underneath, try to put them in a comfortable way that won't hurt. If you have a bladder probe under your leg, for instance, this cannot happen, because it will press. You should put it on top. I always try to put the probe clamp lower, not to leave it on top of the bed so that when making a decubitus change the patient does not stay on top of the clamp. (N4, NT3, NT8)

\section{Cl6: Early assessment and removal of devices when clini- cally possible}

DCS6: I think the need assessment of the device is the most important. It has an invasive device that can cause injury, most of the cases for the time it stays in patients. The sometimes-inattentive professional does not realize that this therapy is no longer necessary. Perhaps a little more evaluation is needed. Sometimes the team has to alert saying "so and so how long has this device been in?" "Is he still needed?" Is it still viable? A patient with an esophageal thermometer, who was in an acute septic condition and who controlled with antibiotics. The temperature is no longer high, so is there no way to pass an axillary temperature assessment? I often see this inattention to patients' reassessment. (NT4)

In five of the six speeches that emerged from the study, ideas were shared between nurses and nursing technicians, which shows that care they reveal represents those implemented by the nursing team in MDR PI prevention in critically ill patients. DCS6 was the only one made up of the testimony of only one participant (ET), which allows us to infer that "Early assessment and removal of devices, when clinically possible" $(\mathrm{Cl})$ is not a care implemented by the entire nursing team.

\section{DISCUSSION}

With regards to the interviewed professionals' profile, in line with another study ${ }^{(9)}$, there was a predominance of young female adults with experience in intensive care. Professional qualification search by participants was notorious, since most of them are trained in undergraduate and graduate courses.

Care regarding medical device fixation is described in DCS1. Appropriate fixator and support fixation use were recommended by professionals to avoid injuries by catheters such as nasogastric and nasoenteral. Pls related to these devices are underestimated in clinical practice and rarely reported in the scientific literature. Inadequate fixation around the nostril quickly induces tissue ischemia, leading to lesion formation ${ }^{(13)}$. A systematic review ${ }^{(14)}$ on the subject concluded that there is insufficient evidence to suggest a fixation technique or device over another. However, daily fixation changes alternating the position of the nostrils are recommended for PI prevention ${ }^{(15)}$.

Regarding the fixation of the orotracheal tube (OTT), the importance of keeping the ear region free was approached, using three different techniques, all using cotton laces. The professionals mentioned the existence of other types of fixators for OTT; however, these are not standardized in the research setting. The indication of commercial fasteners for OTT is controversial. A survey ${ }^{(16)}$ that compared conventional fixation methods and commercial fixers found that these devices put more pressure on the face than noncommercial devices. Another study ${ }^{(17)}$ observed that using a specific commercial fixative increased oral $\mathrm{Pl}$ incidence in intubated patients.

The OTT fixation technique, called "helmet" (Figure 1), mentioned by participants, is routinely used in the institution where the study was developed. The use of this technique aims to keep the ears free from pressure. However, there is no evidence to support its recommendation for MDR PI prevention.

In order to prevent injuries resulting from delayed bladder catheters, participants indicated its fixation, preferably with a standardized device. According to the literature ${ }^{(18)}$, these devices must be fixed securely and with specific materials to avoid injuries to the urethra and other adverse events related to the device.

In DCS2, care is indicated regarding the periodic repositioning of medical devices, such as alternating fingers for the pulse oximeter, rotating the labial commissure for OTT and cardiac monitoring electrodes, in addition to alternating the nostril position for the nasogastric catheters and nasoenteral.

Careful inspection of the skin and changing the position of the devices, when possible, is essential for PI identification and prevention. A study ${ }^{(19)}$ carried out in the United States showed that $74 \%$ of MDR PIs were only detected when in stage 3 or 4, indicating late recognition of them. Frequent repositioning of the devices, in addition to relieving pressure, allows the first signs of injury to be identified, and thus preventive or treatment measures are promptly implemented. 


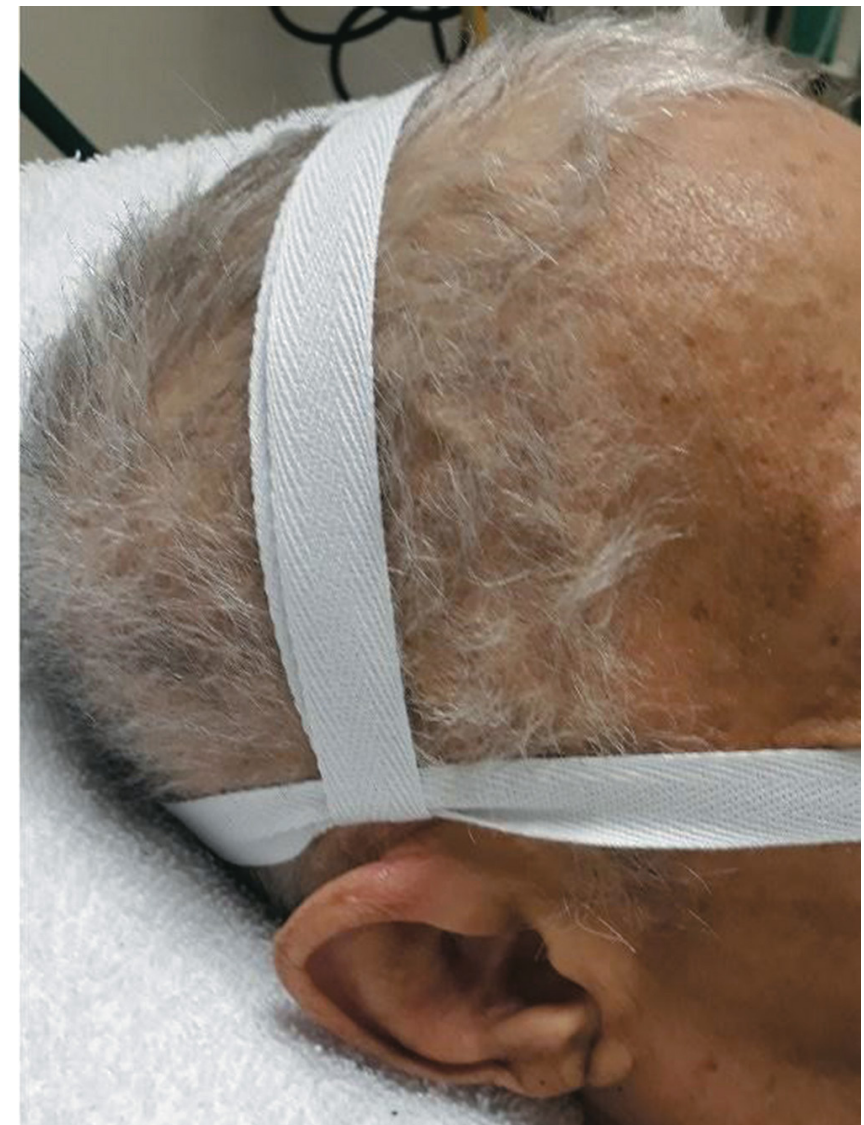

Figure 1 - Helmet technique for orotracheal tube fixation

The rotation of the labial commissure for OTT was also pointed out in a Brazilian study ${ }^{(20)}$, in which $40 \%$ of the interviewed nurses considered this care as the most important to avoid injuries and oral fissures associated with the device. Supporting this, a study carried out ${ }^{(21)}$ in the United States showed a reduction in the prevalence of OTT-related injuries from $16 \%$ to $10 \%$, when the repositioning of this device was performed every 4 hours instead of every 12 hours.

Although essential, this care can sometimes be neglected by the team. A study ${ }^{(6)}$ carried out with Australian nurses revealed that the repositioning and assessment of the skin under the device is often overlooked or little valued in the critical care setting, concluding that many professionals are unaware of the preventive strategies for MDR PI or the implications of these adverse events.

Regarding PI risk assessment, there are validated scales that can be used by professionals. According to the International Consensus ${ }^{(7)}$, the Braden QD scale has shown to have an acceptable predictive value for assessing the risk of MDR PI in the context of pediatric intensive care from the relationship between physical immobility and invasive device use in patients up to 21 years old, including newborns. In the adult population, the Braden scale, although not specific for assessing injuries by devices, proved to be sensitive in a study conducted in Turkey, in which the prevalence of these injuries was higher in patients who had a lower Braden score ${ }^{(22)}$.

The protection and padding of body areas in contact with the medical device was recommended in DCS3 using dry gauze or gauze moistened with essential fatty acids (EFC) in the ear and lip region of patients with OTT. The hydrocolloid plate is applied to the base of the nose for patients with a non-invasive ventilation mask (NIV) and nostril for patients using a nasogastric and nasoenteral catheter.

The effectiveness of using gauze was questioned by professionals in this speech. The adaptation and improvisation of materials in the hospital context is part of the daily life of many nursing workers. As a Brazilian research revealed, this is a dialectical practice, with feelings of suffering and pleasure. This is because, while ensuring care, it also puts the safety of patients and workers at risk ${ }^{(23)}$.

With regard to commercial protector use, a study carried out in Turkey ${ }^{(9)}$, with 606 nurses, found that $78.5 \%$ used to use protective dressings in places where medical devices and fixation elements were placed. A meta-analysis of randomized studies ${ }^{(24)}$ indicated that using hydrocolloid plaque significantly decreases the incidence of facial PI related to NIV masks.

Regarding padding with protective foam, the benefits are substantial for MDR PI prevention, with a reduction of $83 \%$ of cases after using these dressings, associated with the surveillance of the risk sites and repositioning of the devices by the health team ${ }^{(25)}$. However, caution is needed, avoiding overuse or multiple layers of dressings, as this can increase the pressure exerted between the device and the skin ${ }^{(26)}$.

Factor that must also be considered is the characteristic of medical devices, given that many are made or fixed with rigid materials, which can cause friction and increased pressure on tissues, resulting in injuries ${ }^{(19)}$. The replacement of rigid devices with flexible devices when available was pointed out as a preventive measure in DCS4.

Evidence suggests ${ }^{(27)}$ that the selection of devices made of softer and more elastic materials, particularly at points that come into contact with patients' skin, is an important care to prevent MDR PI. Unfortunately, malleable products are associated with increased costs and may have financial repercussions for the institution, which sometimes limits their use. One solution may be to use these special products in a unit that has a higher incidence of MDR PI, such as ICU ${ }^{(26)}$.

In DCS5, participants reported the need for professional attention so that devices do not come under patients with impaired/ bedridden mobility. In this sense, professionals should check for the presence of loose devices on the bed, especially when performing decubitus changes. This care is described in the European guideline ${ }^{(28)}$, which recommends, for MDR PI prevention, that one should avoid placing the individual in direct contact with medical devices, such as tubes, drainage systems or other foreign objects, unless this is the case cannot be avoided.

Equally important care for MDR PI prevention, mentioned in DCS6, was the need for professionals to pay attention to the early evaluation and removal of the device, when possible, and/ or its replacement with another with a lower risk of injury. The golden rule in PI treatment and prevention is to find the cause of the pressure and remove it, therefore it is crucial to remove the devices, as soon as clinically viable, to minimize the risk, which requires vigilance and careful evaluation at the edge of the bed by the multidisciplinary team ${ }^{(9)}$.

Analysis of all speeches points out that nursing care is key to MDR PI prevention, associated with multidisciplinary conduct, especially with regard to the assessment of maintenance of devices. Furthermore, the production of knowledge to support 
evidence-based practices is essential, since some behaviors are still based on empiricism and without institutional standardization.

The gap that still exists between research and practice is highlighted, which makes it difficult to implement evidence in the work processes and professional practice of nurses, who consequently use the best available evidence instead of the best possible ${ }^{(29)}$. Another issue refers to the need for technological innovations and specific materials for fixing devices and protecting risk areas, considering that many conducts are improvised by nursing professionals who use materials that they consider unsuitable for the purpose.

Permanent education about MDR PI prevention measures is also a fundamental element for the implementation of patient care and safety, since, in the speeches, it cannot be inferred that the set of interventions are the domain of all health professionals in ICU nursing.

Meanwhile, a study carried out in Singapore ${ }^{(30)}$ revealed that one of the challenges faced by nursing professionals to prevent MDR PI was the lack of knowledge and the lack of regular training programs. A recent systematic review and meta-analysis ${ }^{(31)}$ showed that education and training programs for PI can improve the knowledge and clinical judgment of nurses in the prevention and treatment of these injuries, and should be encouraged in health institutions.

\section{Study limitations}

The present study was limited to the reality of only one ICU, which prevents the generalization of data.

\section{Contributions to nursing, health, and public policy}

The contribution of this study is in the description of nursing care for MDR PI prevention, which can support the development of clinical guidelines and protocols for similar contexts, promoting quality of care and safety for critical patients.

\section{FINAL CONSIDERATIONS}

As preventive measures for MDR PI, the nursing team exposed important aspects regarding the devices: nursing care when fixing devices; frequent repositioning; protection and padding of body areas in contact; replacement of rigid devices with flexible devices, when available; professionals' attention so that devices do not come under patients; early assessment and removal of devices, when clinically possible, and/or replacement of these by others with less risk of injury.

Preventive care was directed mainly to respiratory devices, such as OTT and NIV; nasogastric, nasoenteral and vesical catheters; and monitoring equipment, such as electrodes and pulse oximeter. However, many of these recommendations can be applied to other devices, such as venous catheters.

Analysis of all speeches showed that nursing professionals have knowledge about MDR PI prevention, since most of the care mentioned converges with the literature, a fact that may be associated with participants' academic qualifications. However, it is not possible to affirm the routine application of this care in care, which points to the need for further research on the conformity between discourse and professional practice.

\section{FUNDING}

This work was supported by the Coordination for the Improvement of Higher Education Personnel - Brazil (CAPES - Coordenação de Aperfeiçoamento de Pessoal de Nível Superior) - Financing Code 001.

\section{REFERENCES}

1. Edsberg LE, Black JM, Goldberg M, McNichol L, Moore L, Sieggreen M. Revised national pressure ulcer advisory panel pressure injury staging system: revised pressure injury staging system. J Wound Ostomy Continence Nurs. 2016;43(6):585-97. https://doi.org/10.1097/won.0000000000000281

2. Coyer F, Cook JL, Brown W, Vann A, Doubrovsky A. Securement to prevent device-related pressure injuries in the intensive care unit: a randomised controlled feasibility study. Int Wound J. 2020; 1-12. https://doi.org/10.1111/iwj.13432

3. Delmore B, Ayello EA. Pressure injuries caused by medical devices and other objects: a clinical update. Am J Nurs. 2017;117(12):36-45. https:// doi.org/10.1097/01.NAJ.0000527460.93222.31

4. Coyer F, Tayyib N. Risk factors for pressure injury development in critically ill patients in the intensive care unit: a systematic review protocol. Syst Rev. 2017;6(1):58. https://doi.org/10.1186/s13643-017-0451-5

5. Cavalcanti EO, Kamada I. Medical-device-related pressure injury on adults: an integrative review. Texto Contexto Enferm. 2020;29:e20180371. https://doi.org/10.1590/1980-265x-tce-2018-0371

6. Barakat-Johnson M, Barnett C, Wand T, White K. Medical device-related pressure injuries: an exploratory descriptive study in an acute tertiary hospital in Australia. J Tissue Viability. 2017;26(4):246-53. https://doi.org/10.1016/j.jtv.2017.09.008

7. Gefen A, Ousey K. Update to device-related pressure ulcers: secure prevention. Covid-19, face masks and skin damage. J Wound Care. 2020; 29(7). https://doi.org/10.12968/jowc.2020.29.7.379

8. Gefen A, Alves P, Ciprandi G, Coyer F, Milne CT, Ousey K, et al. Device-related pressure ulcers: secure prevention. J Wound Care. 2020; 29(sup2a). https://doi.org/10.12968/jowc.2020.29.Sup2a.S1

9. Karadag A, Hanönü SC, Eyikara E. A prospective, descriptive study to assess nursing staff perceptions of and interventions to prevent medical device-related pressure injury. Ostomy Wound Manage. 2017;63(10):34-41. https://doi.org/10.25270/owm.2017.10.34412017

10. Galetto SGS, Nascimento ERP, Hermida PMV, Malfussi LBH. Medical device-related pressure injuries: an integrative literature review. Rev Bras Enferm. 2019;72(2):505-12. https://doi.org/10.1590/0034-7167-2018-0530 
11. Fontanella BJB, Luchesi BM, Saidel MGB, Ricas J, Turato ER, Melo DG. [Sampling in qualitative research: a proposal for procedures to detect theoretical saturation]. Cad Saude Publica. 2011;27(2):388-94. https://doi.org/http://dx.doi.org/10.1590/S0102-311X2011000200020 Portuguese

12. Lefevre F, Lefevre AMC. Pesquisa de representação social: um enfoque qualiquantitativo: a metodologia do Discurso do Sujeito Coletivo. Brasília: Liber Livro; 2012

13. Asti E, Sironi A, Milito P, Bonavina G, Bonitta G, Bonavina L. Prevalence and risk factors of nasal pressure ulcers related to nasogastric intubation: an observational study. Eur Surg. 2017;49(4):171-4. https://doi.org/10.1007/s10353-017-0476-y

14. Brugnolli A, Ambrosi E, Canzan F, Saiani L. Securing of naso-gastric tubes in adult patients: a review. Int J Nurs Stud. 2014;51(6):943-50. https:// doi.org/10.1016/j.ijnurstu.2013.12.002

15. Busanello J, Pinto DM, Schons ES, Baumgart D, Poll MA. [Nursing care to adult patient: mucocutaneous injuries prevention and patient safety]. Rev Enferm UFSM. 2015;5(4):597-606. https://doi.org/10.5902/2179769216310 Portuguese

16. Fisher DF, Chenelle CT, Marchese AD, Kratohvil JP, Kacmarek RM. Comparison of commercial and noncommercial endotracheal tube-securing devices. Respir Care. 2014;59(9):1315-23. https://doi.org/10.4187/respcare.02951

17. Hampson J, Green C, Stewart J, Armitstead L, Degan G, Aubrey A, et al. Impact of the introduction of an endotracheal tube attachment device on the incidence and severity of oral pressure injuries in the intensive care unit: a retrospective observational study. BMC Nurs. 2018;17:4. https://doi.org/10.1186/s12912-018-0274-2

18. Shum A, Wong KS, Sankaran K, Goh ML. Securement of the indwelling urinary catheter for adult patients: a best practice implementation. Int J Evid Based Healthc. 2017;15(1):3-12. https://doi.org/10.1097/XEB.0000000000000084

19. Black J, Alves P, Brindle CT, Dealey C, Santamaria N, Call E, et al. Use of wound dressings to enhance prevention of pressure ulcers caused by medical devices. Int Wound J. 2015;12(3):322-7. https://doi.org/10.1111/iwj.12111

20. Pinto DM, Schons ES, Busanello J, Costa VZ. Patient safety and the prevention of skin and mucosal lesions associated with airway invasive devices. Rev Esc Enferm USP. 2015;49(5):775-82. https://doi.org/10.1590/S0080-623420150000500010

21. Mussa CC, Meksraityte E, Li J, Gulczynski B, Liu J, Kuruc A. Factors associated with endotracheal tube related pressureinjury. SM J Nurs [Internet]. 2018 [cited 2020 Jan 21];4(1):1018-23. Available from: https://smjournals.com/nursing/fulltext/smjn-v4-1018.pdf

22. Hanonu S, Karadag A. A prospective, descriptive study to determine the rate and characteristics of and risk factors for the development of medical device-related pressure ulcers in intensive care units. Ostomy Wound Manage [Internet]. 2016 [cited 2020 Jan 21];62(2):12-22. Available from: https://pubmed.ncbi.nlm.nih.gov/26901386/

23. Cunha LS, Souza NVDO, Gonçalves FGA, Santos DM, Ribeiro LV, Pires AS. Hospital nursing: the dialectics of adapting and improvising in practice. Rev Enferm UERJ. 2016;24(5):1-6. https://doi.org/10.12957/reuerj.2016.18835

24. Cai JY, Zha ML, Chen HL. Use of a hydrocolloid dressing in the prevention of device-related pressure ulcers during noninvasive ventilation: a meta-analysis of randomized controlled trials. Wound Manag Prev [Internet]. 2019 [cited 2020 Jan 21];65(2):30-8. Available from: https:// www.o-wm.com/article/use-hydrocolloid-dressing-prevention-device-related-pressure-ulcers-during-noninvasive

25. Cooper DN, Jones SL, Currie LA. Against all odds: preventing pressure ulcers in high-risk cardiac surgery patients. Critical Care Nurse. 2015;35(5):76-82. https://doi.org/10.4037/ccn2015434

26. Dyer A. Ten top tips: preventing device-related pressure ulcers. Wounds Int [Internet]. 2015 [cited 2020 Jan 21];6(1):9-13. Available from: https:// www.woundsinternational.com/resources/details/ten-top-tips-preventing-device-related-pressure-ulcers

27. Hasler E. Pressure injuries: preventing medical device related pressure injuries. Wound Practice and Research [Internet]. 2017 [cited 2020 Jan 21];25(4):214-16. Available from: https://journals.cambridgemedia.com.au/application/files/3115/8572/5924/summary03.pdf

28. European Pressure Ulcer Advisory Panel. National pressure injury advisory panel and pan pacific pressure injury aliance. Prevention and treatment of pressure ulcers/injuries: quick reference guide. [Internet]. Cambridge: EPUAP; 2019 [cited 2020 Jan 21]. Available from: https:// guidelinesales.com/

29. Danski M, Rodrigues GL, Pedrolo E, Lind J, Johann D. Importance of evidence-based practice in nurse's work processes. Cienc Cuid Saude. 2017;16(2):1-6. https://doi.org/10.4025/cienccuidsaude.v16i2.36304

30. Tan JJM, Cheng MTM, Hassan NB, He H, Wang W. Nurses' perception and experiences towards medical device-related pressure injuries: a qualitative study. J Clin Nurs. 2020;29:2455-65. https://doi.org/10.1111/jocn.15262

31. Park M, Kim G, Kim K. The effect of pressure injury training for nurses: a systematic review and meta-analysis. Adv Skin Wound Care. 2020;33(3):1-11. https://doi.org/10.1097/01.ASW.0000653164.21235.27 